\title{
Endoscopic submucosal dissection with double-tunnel technique for en bloc resection of large rectal laterally spreading tumor
}

\author{
Stefanos P. Bassioukas ${ }^{\mathrm{a}}$, Charalampis Katzakis ${ }^{\mathrm{a}}$, Christos Kitsios ${ }^{\mathrm{a}}$, Akrivi Pantazopoulou ${ }^{\mathrm{b}}$
}

Bioclinic Hospital; Histobio Diagnosis Laboratory, Athens, Greece

Large $(>2.5 \mathrm{~cm})$ rectal laterally spreading tumors (LSTs) are often managed endoscopically with piecemeal endoscopic mucosal resection technique (pEMR). However, the mean recurrence rate after pEMR is 20\% [1]. Furthermore, rectal LST-mixed granular type lesions (0-Is+IIa) demonstrate deep submucosal cancerous infiltration in $10.1 \%$ of cases [2]. Endoscopic submucosal dissection (ESD) is an endoscopic technique developed in Japan for the en bloc excision of gastrointestinal superficial tumors with the intent to perform precise histopathological staging, offering an almost null risk of recurrence.

Here we report the case of a 74-year-old woman with a rectal LST-G mixed type tumor occupying $90 \%$ of the circumference of the dentate line and extending into the rectum. Endoscopic biopsies revealed a low-grade and focally a high-grade adenoma.

We performed en bloc excision of the tumor with the ESD technique, using a Dual-Jet Knife (Olympus Corporation, Japan) and an Olympus GIF-HQ190 endoscope. ESD was performed under general anesthesia and 2 submucosal tunnels were initially achieved from the anal to the oral side (Fig. 1). For very large LSTs tunneling ESD offers a precise dissection plane without loss of orientation [3]. The dissection was completed by connecting the two tunnels and further dissecting to the periphery of the lesion. The specimen size was $141 \times 82 \mathrm{~mm}$ when fixed on the cork (Fig. 2). Hydrocortisone solution was injected into residual submucosal areas of the artificial ulcer to reduce the risk of rectal stenosis. The procedure lasted $232 \mathrm{~min}$ without complications and the patient was discharged from the hospital the next day. Histology revealed a predominately low-grade adenoma with 5 foci of intramucosal cancer. The procedure was deemed to be an R0/curative resection.

\footnotetext{
${ }^{a}$ Department of Advanced Therapeutic Endoscopy, Bioclinic Hospital (Stefanos P. Bassioukas, Lambis Hatzakis, Christos Kitsios); ${ }^{\text {bHistobio }}$ Diagnosis Laboratory (Akrivi Pantazopoulou), Athens, Greece

Conflict of Interest: None

Correspondence to: Stefanos P. Bassioukas, Director of Advanced Therapeutic Endoscopy Department, Bioclinic Hospital, Athens, Greece, Geroulanou Marinou 15, 11524 Athens, Greece, e-mail: sbassioukas@gmail.com
}

Received 1 July 2017; accepted 5 July 2017; published online 25 July 2017

DOI: https://doi.org/10.20524/aog.2017.0179

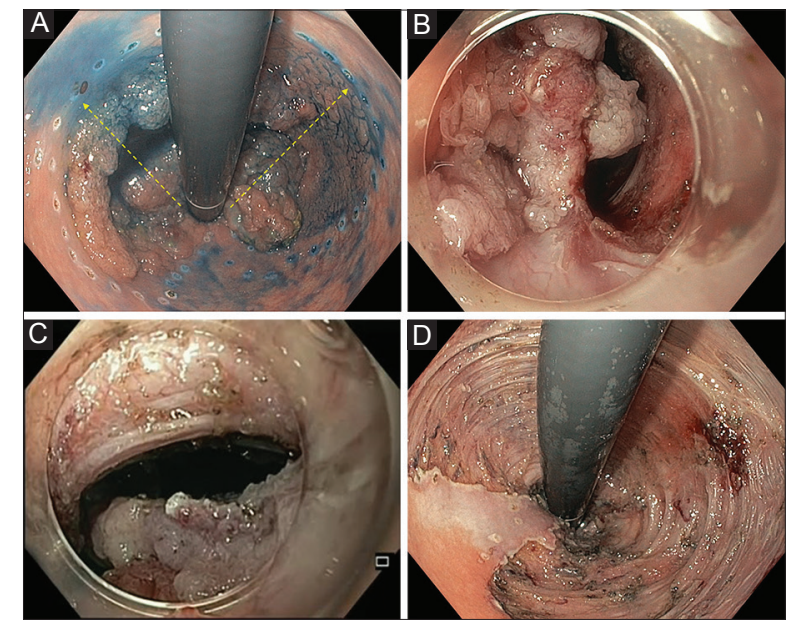

Figure 1 (A) Rectal laterally spreading tumor under retroflexed view. Arrows indicate the direction of the 2 tunnels. (B) First tunnel. (C) Second tunnel. (D) Artificial ulcer after dissection

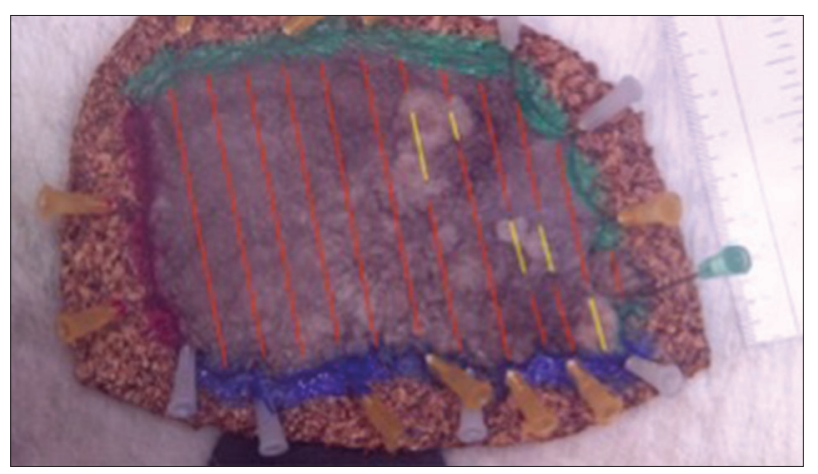

Figure 2 The specimen fixed on the cork. Red lines indicate low-grade dysplastic changes. Yellow lines indicate foci of intramucosal cancer

\section{References}

1. Belderbos TD, Leenders M, Moons LM, Siersema PD. Local recurrence after endoscopic mucosal resection of nonpedunculated colorectal lesions: systematic review and meta-analysis. Endoscopy 2014;46:388-402.

2. Burgess NG, Hourigan LF, Zanati SA, et al. Risk stratification for covert invasive cancer among patients referred for colonic endoscopic mucosal resection: A large multi-center cohort. Gastroenterology 2017 Jun 2. pii: S0016-5085(17)35689-5. doi: 10.1053/j.gastro.2017.05.047. [Epub ahead of print].

3. Aslan F, Akpinar Z, Yurtlu DA, Kucuk M, Ekinci N, Unsal B. Single tunneling method with endoscopic submucosal dissection for treatment of a rectal giant $(18-\mathrm{cm})$ laterally spreading tumor. Endoscopy 2017;49:E114-E116. 